Ю.Н. Казаков, С.А. Колобаев

\title{
ЭКСПЕРИМЕНТАЛЬНОЕ ИЗУЧЕНИЕ ФЕНОМЕНА ТЕЛЕСНОСТИ В ГРУППЕ СПОРТСМЕНОВ САМБО И ДЗЮДО
}

\begin{abstract}
Аннотация. Предметом исследования данной статьи структура, содержание и нагрузки факторов, слагающих психолого-акмеологический феномен телесности спортсмена. Автор рассматривает телесность как систему психологических процессов, свойств и состояний в переживании и восприятии личностью своего телесного опыта. Гипотезой исследования является наличие психологических взаимосвязей между психологическими явлениями и телесностью, обуславливающими стрессоустойчивость в структуре психического здоровья спортсменов.

Проведено экспериментальное эмпирическое исследование феномена телесности в группе профессиональных спортсменов самбо и дзюдо. Выборка уравнена по возрасту (16-23 лет) и стажу занятий (5-8 лет). Использованы стандартизированные психологические методики, акмеологические методики и авторские методики изучения феномена телесности: полустандартизованное интервью, самооценка телесных параметров психического здоровья (С.А. Колобаев, Ю.Н. Казаков), методика ранжирования телесных параметров, тестирование по методикам Mini-Mult, FPI, опросник темперамента и характера О.Н. Маноловой, акмеография (В.Г. Зазыкин, И.Н. Носс) уровня самоактуализации и самореализации, спортивного профессионализма, Самоактуализационный тест (Э. Шостром). Формирующий эксперимент, интерпретация полученных результатов. Результаты исследования вносились в базу данных (EXCEL) и подвергались статистическому коррелячионному и факторному анализу с помощью программы IBM SPSS Statistics 20.

В исследовании показано, что наиболее релевантные в диагностическом плане методы изучения телесности являются полустандартизированное интервью редлексии телесности, самооценка и ранжирование телесных параметров. Показаны варианты корреляций полученных переменных и факторные нагрузки феномена телесности. Обсуждаются проблемы объединения корреляций в когнитивный, эмоциональный, поведенческий, социальный и перцептивный факторы изучения телесности. Даются рекомендации к развитию личности и оптимизации феномена телесности. Основными выводами проведённого исследования являются психологические взаимосвязи структуры, содержания и нагрузок факторов феномена телесности с уровнем стрессоустойчивости и безопасности психического здоровья.

Ключевые слова: феномен телесности, психолого-акмеологические методы, психология спорта, факторные нагрузки, агрессивность спортсменов, телесные параметры, психологические взаимосвязи, стрессоустойчивость, психическое здоровье, безопасность.
\end{abstract}

Review. The object of research in this article is the structure, contents and factors of the psychological and acmeological phenomenon of physicality of an athlete. The author considers physicality as a system of psychological processes, properties and states that arise in the course of personal experience and perception of physicality. The hypothesis of research is that there are psychological interrelations between psychological phenomena and physicality that cause resistance to stress in the structure of mental health of athletes. Pilot research of the physicality phenomenon in a group of professional sambo and judo athletes is conducted. Athletes aged 16-23 years old with 5-8 years of experience in sambo and judo have been selected to participate in the research. The standardized psychological techniques, acmeological techniques and the author's own techniques for studying the physicality phenomenon are used including the following: the semi-standardized interview, self-assessment of the physical parameters of mental health (Kazakov Yu.N., Kolobaev S.A.,) technique of ranging of physical parameters, testing according to Mini-Mult and FPI methods, O.N. Manolova's temperament and character questionnaire, acmeography of the level of self-actualization, 


\section{Тело и телесность}

self-realization and professional skills in sport (V. G. Zazykin,I. N. Noss) and self-actualization test (E. Shostr). The methods of the formative assessment and interpretation of the received results are also applied. The results of research ha brve beenought in a database (EXCEL) and exposed to the statistical correlation and factorial analysis by means of the IBM SPSS Statistics 20 program. The results demonstrate that the most relevant diagnostic methods of studying physicality are the semi-standardized interview, self-assessment and ranging of physical parameters. Options of correlations of the received variables and factor loadings of the physicaity phenomenon are shown. Problems of association of correlations in cognitive, emotional, behavioural, social and perceptual factors of studying physicality are discussed. Recommendations on personality development and optimization of the physicality phenomenon are made. The main conclusions of the conducted research include psychological interrelations of the structure, contents and factor loadings of the physicality phenomenon with the level of resistance to stress and safety of mental health.

Keywords: mental health, resistance to stress, psychological interrelations, physicality phenomenon, psychologicalacmeological methods, sport psychology, factor loading, aggression of athletes, physical parameters, safety.

$\mathrm{T}$

елесность человека является видной проблемой психологической науки и практики. Рассмотрение телесности на клиническом материале показало неразрывную связь соматического статуса и представление о своём теле с психическими процессами в группе пациентов [1; 2]. Культурологические дискурс обозначил неразрывную связь психики и тела в аспекте выделения концепции биологического и социального тела, и идея трансформации одного тела в другое тело у одного и то же человека, по сути, означая, создание новых тел или телесностей [3]. Философско-антропологические исследования показали неоднородность и неоднозначность понимания и интерпретации феномена телесности $[4 ; 5 ; 6 ; 7 ; 8 ; 9 ; 10]$. Декларируя психосоматическую проблему, основные исследования по психологии телесности сосредоточились на клиническом материале, в сфере физической культуры и спорта, где телесность человека проявляет себя непосредственно, исследования проблем психологии телесности имеют невыделенный и неспецифический характер. Настоящее исследование ставит целью дать описание структуры, содержания и нагрузок факторов, слагающих феномен телесности спортсменов.

Автором проведено экспериментальное эмпирическое исследования феномена телесности. Группа исследования составлена из профессиональных спортсменов самбо и дзюдо. Выбор вида спорта сделан из-за специфики двигательного опыта, технической подготовки и многолетнего стажа занятий. В спортивных единоборствах по литературному обзору отмечается концепция трансформация биологического тела в социальное, созревание телесности нового типа, появление телесных органов и функциональных систем [3; 11; 12; 13;
14; 15]. Размер выборки 30 человек, уравненных по возрасту (16-23 года), уровню образования и спортивному стажу (5-8 лет).

Методология исследования скомбинирована из стандартизированных психологических методик (FPI, Mini-Mult, самоактуализационный тест Шострома), акмеологических методик (акмеографии В.Г. Зазыкина, И.Н. Носс, личностный тест О.Н. Маноловой) и авторских методов изучения телесности. Предложены три методики:

- стандартизированное интервью рефлексии ощущений в формировании технических действий и технической подготовки спортсмена;

- самооценка телесных параметров (эффективности функционирования тела в последовательности актуальных отрезков спортивной деятельности;

- методика ранжирования телесных параметров (по степени субъективной значимости).

Объектом исследования выступил психологоакмеологический феномен телесности профессиональных спортсменов. Предметом является структура, содержание и нагрузки факторов, слагающих психолого-акмеологический феномен телесности спортсмена. Целью исследования служит обоснование психологических взаимосвязей структуры, содержания и нагрузок факторов телесности с уровнем стрессоустойчивости и безопасности психического здоровья. Предлагается гипотеза о наличие психологических взаимосвязей факторов телесности и психического здоровья в статистически значимых нагрузках.

В ходе литературного обзора и теоретической реконструкции материала установлено операциональное определение феномена телесности - система психологических процессов, свойств и состояний в переживании и восприятии личностью своего телесного опыта. 


\section{Психология и психотехника 4(79) • 2015}

Для экспериментальной проверки гипотезы осуществлён сбор эмпирического материала в режиме on-line (дистанционный проведение тестов через электронную почту), off-line (фронтальный сбор материала через контакт со спортсменами индивидуально и в групповом формате).

Результаты тестирования заносились в систеmy Microsoft Excel с последующей обработкой в IBM SPSS Statictics 20.

В ходе исследовании на основании проведённых восьми методик (FPI, Mini-Mult, тест Шострома, акмеограмма, тест Маноловой, уровень рефлексии телесности, самооценка и ранжирование телесных параметров) выделено 140 переменных. Проведено количественное исследование с последующей качественной интерпретацией в формате корреляционного и факторного анализа. Все переменные подверглись двухступенчатому анализу. На первом этапе осуществлён количественный корреляционный анализ по непараметрическому критерию Кендала ( $<$ 0,05). Выбор данного критерия продиктован не-нормальным типом распределения значений в группе, малым размером выборки (n = 30) и способностью учитывать выбросы сверхмалых и сверхвысоких показателей в обсчёте. На втором этапе осуществлён количественный факторный анализ по сведению набора корреляций в значимые факторы по методу главных компонент.

Выделены пять факторов изучения феномена телесности - когнитивный, эмоциональный, поведенческий, социальный, перцептивный. В каждом из пяти факторов феномена телесности присутствуют переменные, отвечающие за уровень стрессоустойчивости и психического здоровья, поэтому описание психологических взаимосвязей данных переменных со структурой, содержанием и нагрузкой факторов будут происходить внутри каждого из факторов.

В когнитивный фактор феномена телесности вошли переменные способностей - управленческих, художественных, словесных и лидерских. Как видно из содержания фактора, данные способности связаны с восприятие и переживание личностью своего телесного опыта. Деятельность, направленная через выражения способностей, реализуется телесной составляющей. Стандартное отклонение показывает стабильность или устойчивость характеристик во всём диапазоне значений. Так, оценка спортсменом своих способности имеет незначительное стандартное отклонение, что говорит о стабильной представленности имеющегося опыта переживания и восприятия телесности и психиче- ских процессов. В когнитивный фактор телесности входят ценностные ориентации. Спортсмены в ходе многолетней тренировки формируют свою телесность исходя из ценностей и предпочтений, выбора конкретного вида спорта (например, борьбы самбо и дзюдо). Притязание на уровень образования играет существенную роль в становлении феномена телесности. Притязания на уровень развития и престижа работы входят в когнитивный фактор, как показатель взаимосвязи с акмеологическими реальностями развития и саморазвития. Интенциональность, или направленность личности спортсмена в развитии и оптимизации своей личностной структуры и телесности выражено в среднем значении самооценки направленности. В направленность в структуре когнитивного фактора феномена телесности входят блоком отдельные, но взаимосвязанные личностные свойства - целеустремлённость, организованность, ответственность, инициативность. Приведённые свойства сопрягаются с лидерскими и управленческими способностями, которые также входят в когнитивный фактор. Когнитивность фактора или его связь с познавательными процессами интерпретируется переменной синергии входящей в фактор, как связующим звеном психических процессов, свойств и состояний. Телесность в когнитивном факторе представлена скоростью моторной - психомоторной характеристикой, отображающей особенности телесности борцов самбо и дзюдо. Ориентировка на представление о природе человека укладывается в когнитивный фактор также, как эргичность интеллектуальная, скорость интеллектуальная и пластичность интеллектуальная.

В эмоциональный фактор феномена телесности вошли переменные самочувствия и активности в средних значениях. Эмоциональность как показательной внутренней среды психики спортсмена выражены активностью и самочувствием также стандартным отклонением - показателем стабильности и устойчивости характеристик. Среди телесных переменных, отображающих состояние внутренней среды организма, его висцеральных систем и саморегуляции является средние значения и стандартные отклонения параметров иммунитета, пищеварения, давления спортсменов самбо и дзюдо. Эмоциональные процессы выражены в свойстве общительности, в самооценке уровня качества общения с друзьями. При этом учитываются уровни экстраверсии-интроверсии. Значимым показателем является притязание на создание хорошей семьи 


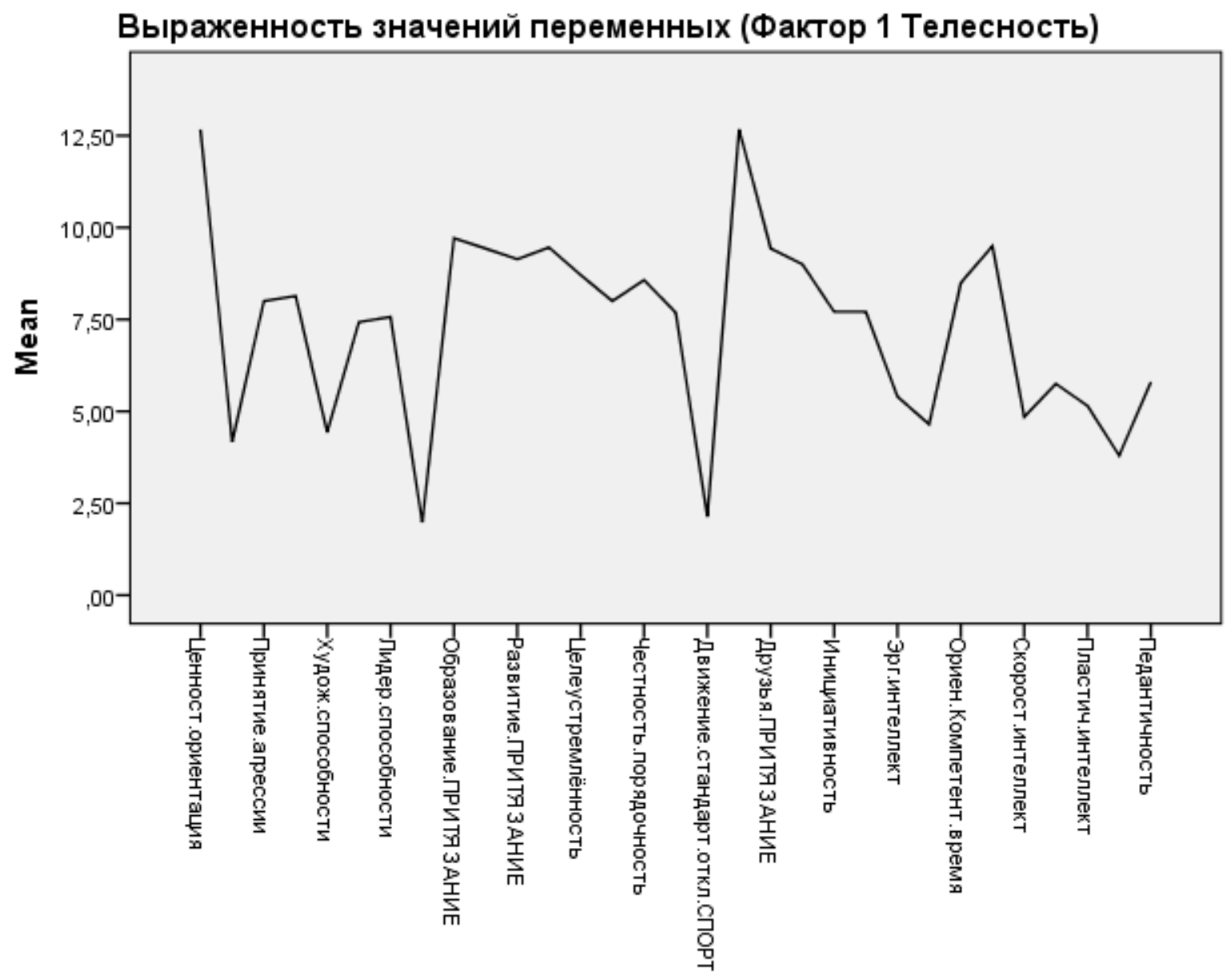

Pис. 1. Simple line charts

«Выраженность значений переменных»

(Фактор 1 Телесность)

или улучшение уже имеющейся. Телесный тренинг спортсменов выражены в оценках своей маскулинности и фемининности. Открытость и стремление к взаимодействию сочетается со спонтанностью в проявлении, презентации себя, отсутствием зависти к успехам других. Застенчивость сопрягается со способностью давать поддержку другим. Складывающая организация тела, именуемая телесность, в группе спортсменов самбо и дзюдо отмечается наличием взаимосвязей с психическими состояниями, свойствами и процессами общения, особенностями проявления эмоций, контакта с группами людей и отдельными индивидуумами.

В поведенческий фактор феномена телесности вошло наибольшее число переменных телесности, что является объяснимым как условие и необходи- мость развёртывания поведения вовне. Поведение человека является комплексом действий, преимущественно включающих моторную и психомоторную составляющую, как отмечают ряд авторов [6; 11; 16; 23; 24]. Во-первых, необходимо показать присутствие переменных средних значений самочувствия, активности, настроения, которые являются центральным звеном поведенческого фактора феномена телесности. Телесные параметры движения, пульса, давления характеризуют поведение и физическое действие. Пищеварение и потоотделение отображают состояния деятельности висцеральных систем. Во-вторых, в структуре поведенческого фактора феномена телесности имеются характеристики стабильности и устойчивости переменных в заданном диапазоне. Прежде 


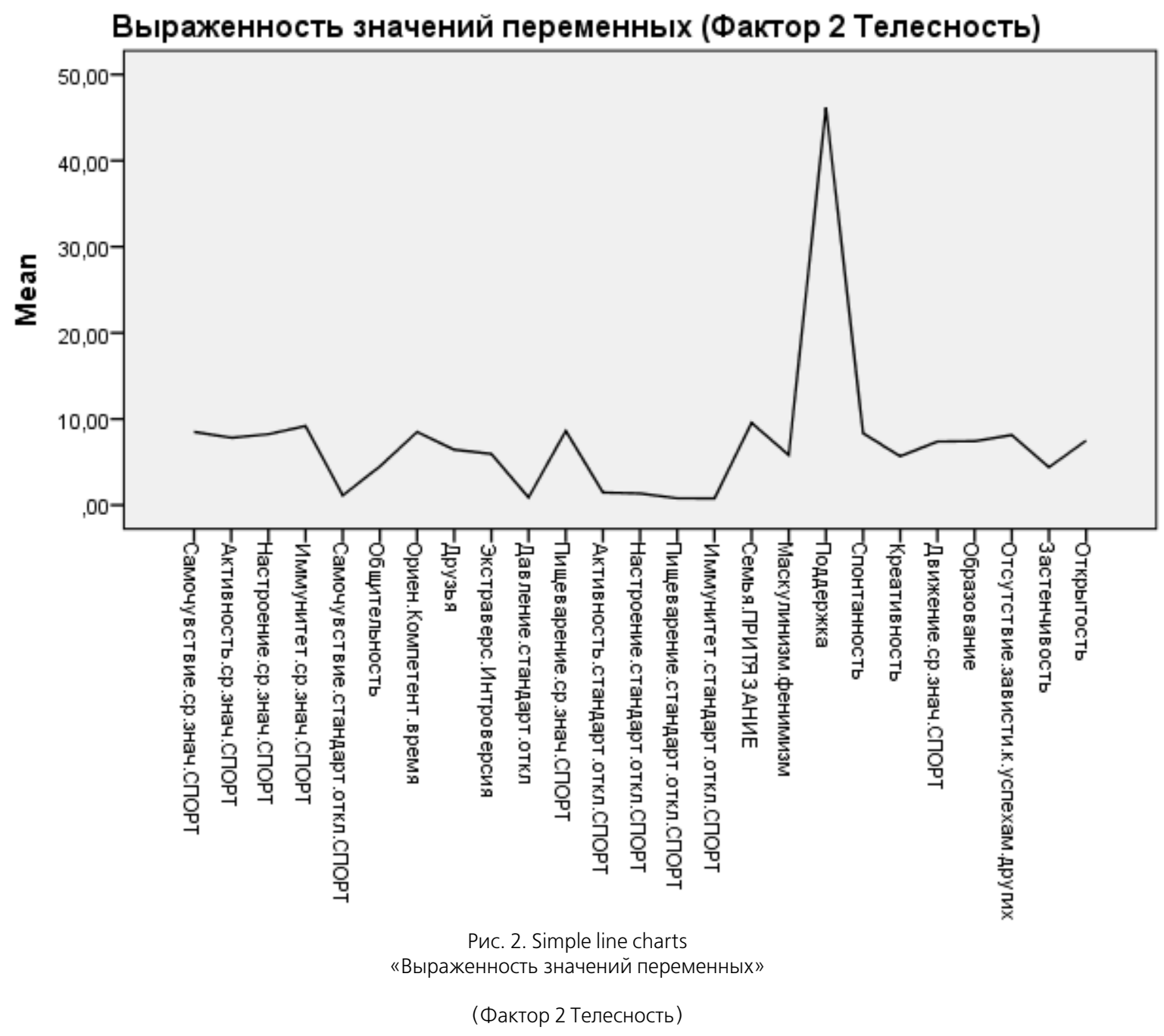

всего в группу значений входят самочувствие, активность, настроение. В ходе физического многолетнего тренинга спортсменами самбо и дзюдо вырабатываются способности к самоконтролю своего состояния - управлению психоэмоциональным и психофизическим состояниям. В третьих, сопутствующим условием эффективного управления состоянием является способности к управлению своим дыханием, способности экономно и эффективно насыщать свой организм необходимым количество кислорода. В данном факторе присутствуют телесные параметры деятельности сердечно-сосудистой и дыхательной систем - пульс, давление, дыхание, движение. Борцы самбо и дзюдо имеют стабильные функциональные системы для преодоления телесных и эмоциональных нагрузок. Регулирующим звеном в поведенческом факторе являются волевые процессы, которые взаимосвязаны с уровнем пластичности или гибкости в развёртывании поведения и коммуникации.

В социальный фактор феномена телесности вошли переменные акмеологической реальности. Факторный анализ по методы главных компонент закономерно вычислил и вместил в социальных фактор именно акмеологические переменные. В данную группу входят показатели социального развития, экономического благополучия, способности достигать успеха в профессиональной деятельности. Спортсмены самбо и дзюдо в рамках профессиональной деятельности обязаны показывать убедительные результаты в тренировочном и соревновательном циклах. Подробный отчёт в профессионально значимых качествах обеспечивает акмеограмма. Внутри данной методики вы- 


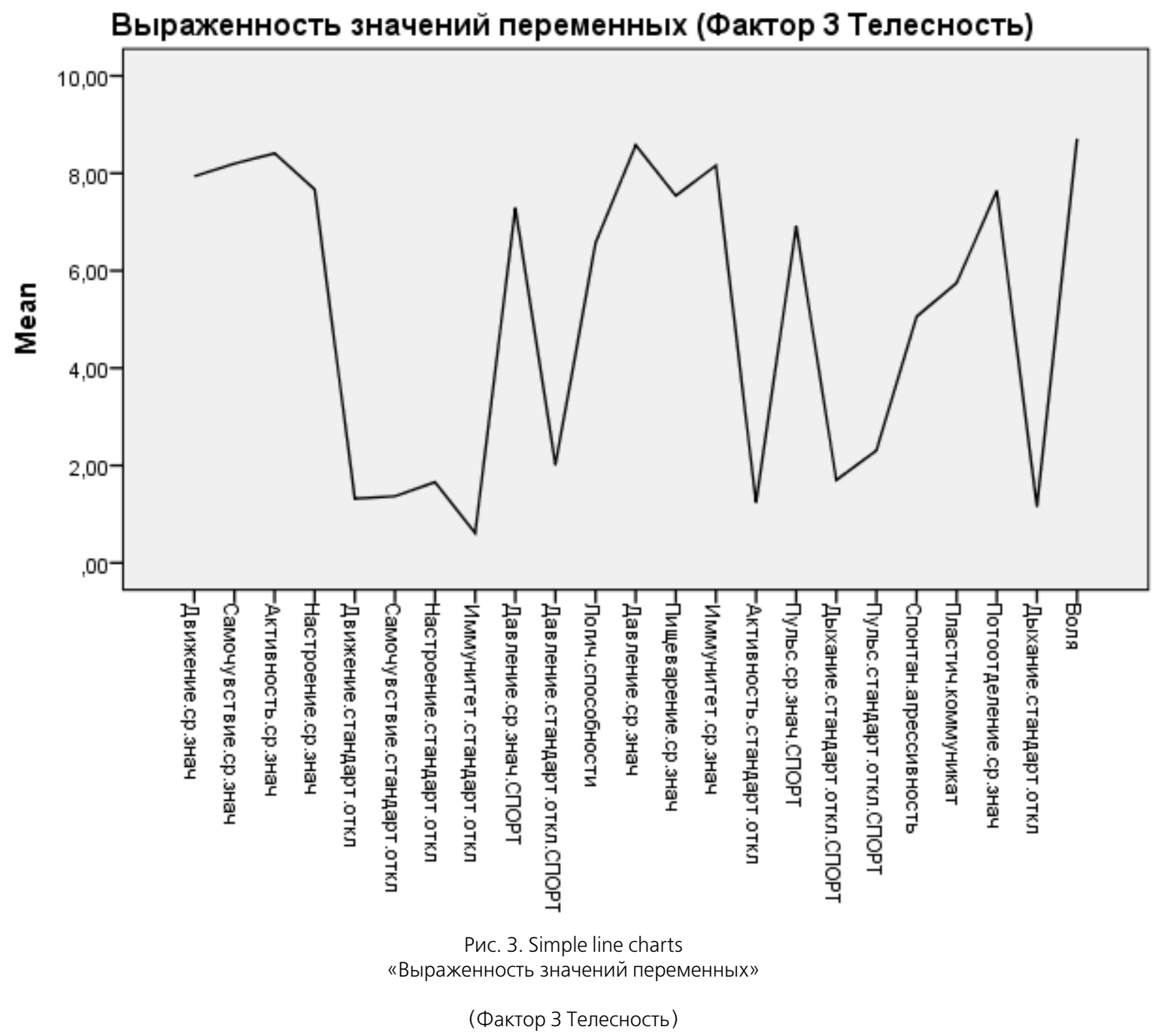

делились показатели, которые вошли в социальный фактор телесности. Прежде всего, это среднее значение самооценки акмеограммы и стандартное отклонение самооценки акмеограммы. Важным звеном социальной активности через развитие телесности является чувствительность и контактность, но в контексте профессионального и социального развития, приобретения материальной и экономической эффективности. Телесность спортсмена в данном факторе коррелирует с оценками на притязания в развитии семьи, карьеры, работы. По мнению ряда авторов $[1 ; 2 ; 5 ; 9]$ социальность является прямо противоположным направлением развития от телесности. В ходе социализации и встраивания органов телесности (приобретения новых функциональных систем) биологическое и социальное тело влияют друг на друга. Спортсмены в профессиональной деятельности закономерно сочетают агрессивность с контактностью и эмоциональностью интеллектуальной, что говорит о психологических взаимосвязях между социальными факторами и телесностью.

В перцептивный фактор феномена телесности вошли переменные, связанные с восприятием и переживанием личности своего опыта. Во-первых, это категория способностей: музыкальных, вокальных, театральных и технических. Способности к освоению профессиональной деятельности сопрягаются с восприятием и переживанием личностью своего телесного опыта. Во-вторых, в перцептивный фактор феномена телесности вошли собственные переменные сензитивности к себе, 


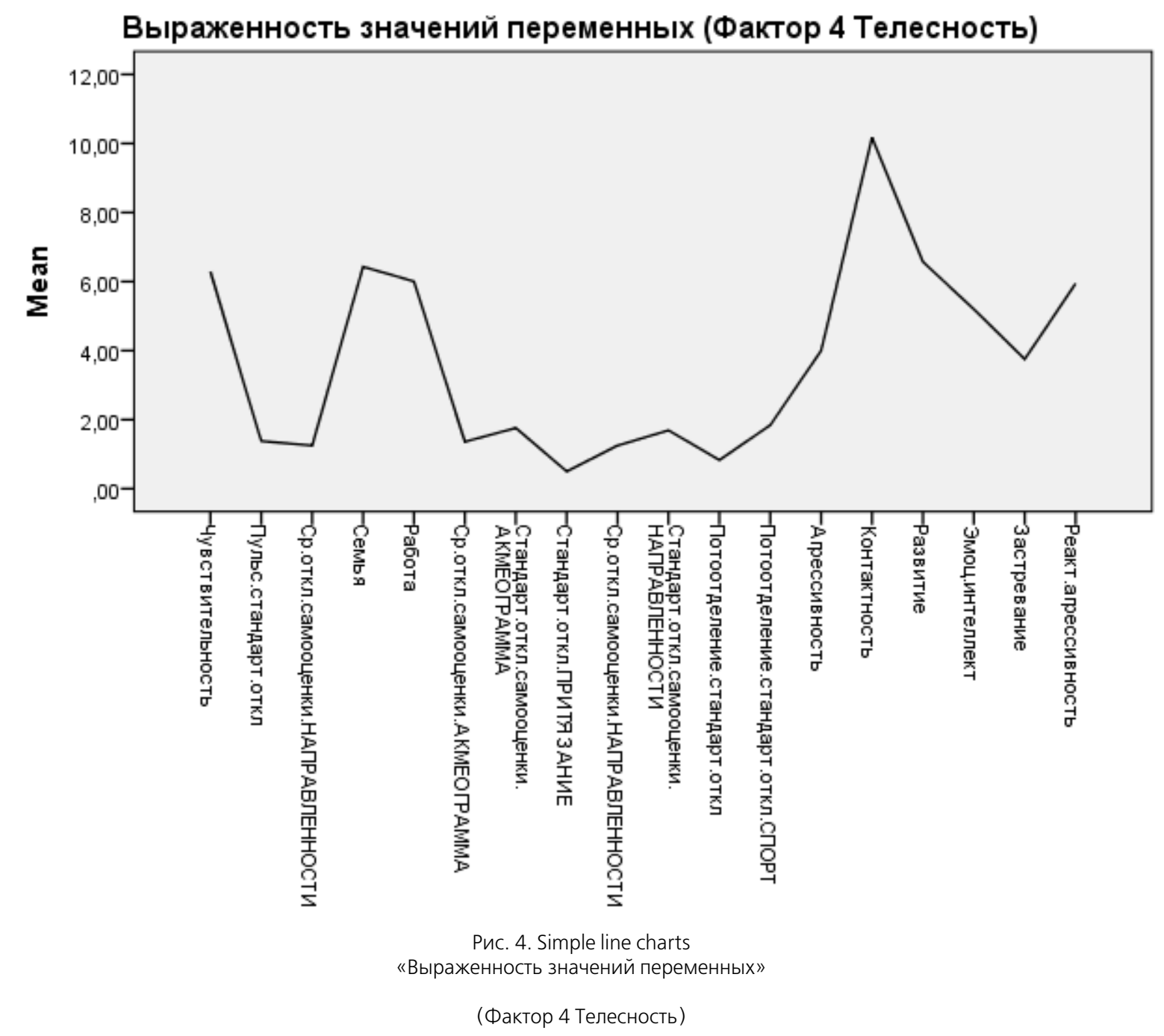

эмоциональности коммуникативной, эргичности коммуникативной и скорости коммуникативной. Эти психические процессы детерминируют социально-перцептивную компетентность. В-третьих, в данный фактор входят переменные эмоциональных процессов - эмотивности, депрессивности, эмоциональной лабильности. На основе перцептивных процессов строится самопринятие как условие и фактор безопасности психического здоровья спортсменов. В ходе тренировок и соревнований спортсмены самбо и дзюдо получают плотный телесный контакты в виде приёмов, бросков, захватов. На физическом уровне существует отработка навыков контакта, взаимодействия и перцепции телесного опыта. В процессе развития физические навыки переходят в психологические навыки, формируя телесность спортсмена. Характеризующими переменными перцептивного фактора феномена телесности являются эргичность моторная и скорость коммуникативная. Психомоторная активность коррелируют с перцептивной составляющей: переживание и восприятие личностью своего телесного опыта закрепляется в перцептивном факторе феномена телесности.

Таким образом, на анализе соотношения значимых корреляций показаны психологические взаимосвязи структуры, содержания и нагрузок факторов телесности. Полученные факторы феномена телесности взаимосвязаны со стрессоустойчивостью и безопасностью психического здоровья спортсменов. Внутри каждого из факторов находятся переменные, отвечающие за безопасность, 


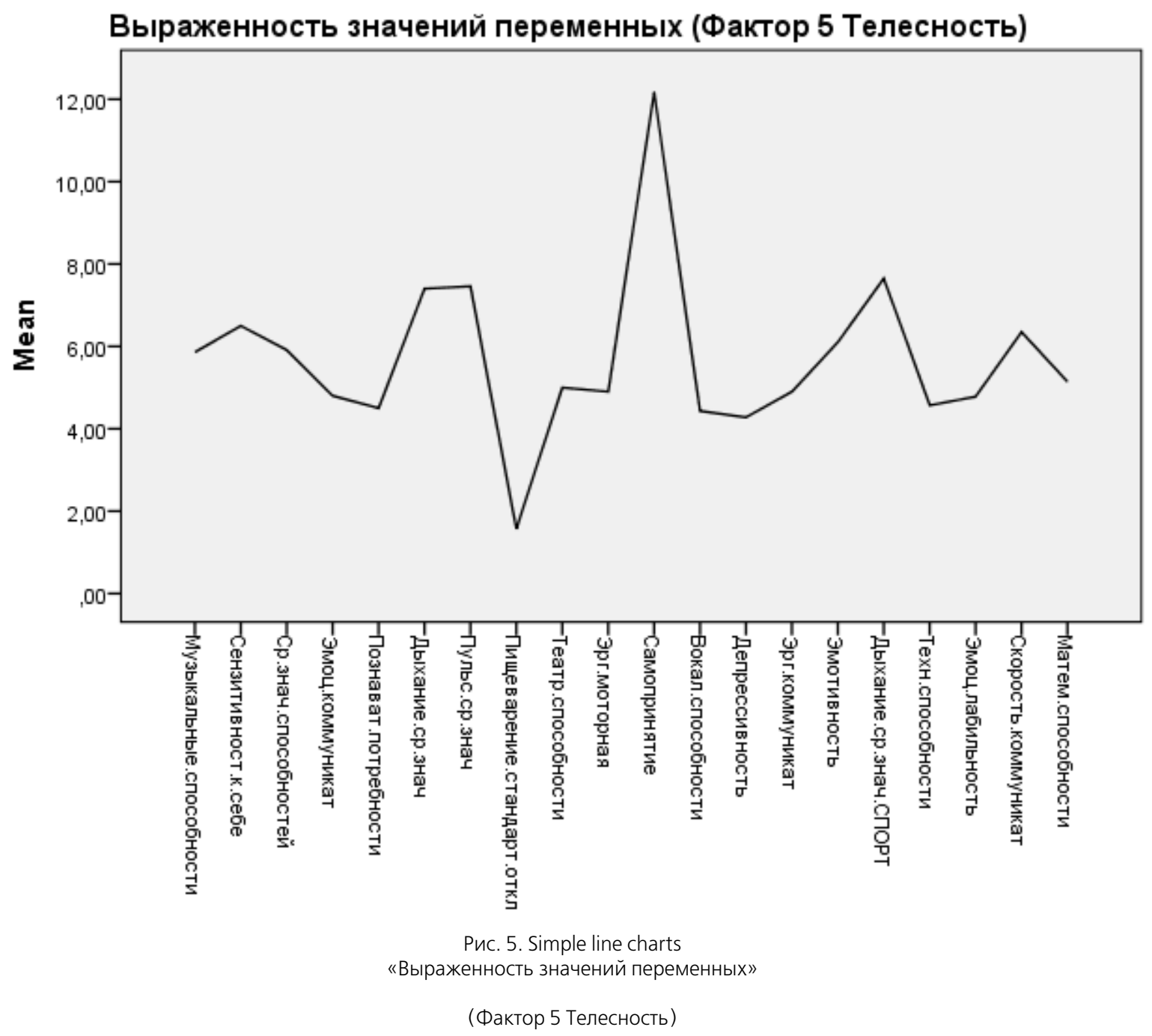

уровень здоровья и устойчивость к экстремальным условиям. Отмечается связь когнитивного, эмоционального, поведенческого, социального и перцептивного факторов феномена телесности в акмеологической реальностью. Формируемая спортсменом в ходе тренировок и соревнования телесность взаимосвязана с притязаниями на карьерные достижения, создание благополучной семьи или укрепления настоящих семейных отношений, развитие материальной и экономической эффективности. К полученным факторам могут быть подобраны методики на диагностику искомых переменных и рекомендации развитию психических процессов, свойств и состояний, слагающий феномен телесности. Методики на диагностику телесности могут выходить за рамки предложенных в настоящем исследовании. Так, под каждую переменную и каждый показатель возможно использовать любые иные стандартизированные психодиагностические методы либо авторские, созданные в процессе эмпирической проверки. Полученные оценки феномена телесности рекомендуются к количественному анализу с применением программ Microsoft Excel и IBM SPSS Statistics. Измерения переменных факторов телесности рекомендует проводить в трёх плоскостях - оценка индивида относительно самого себя, относительного среднего значения в группе и группы относительно самой себя. Под каждую количественную оценка эффективно давать качественную оценку, как пример, теоретическую реконструкцию материала [3] с поиском имеющийся взаимосвязей. 


\section{Психология и психотехника 4(79) • 2015}

Спортсменам самбо и дзюдо на различных уровнях профессионального стажа рекомендуются к регулярному проведению психодиагностические процедуры феномена телесности. Полученные измеренные факторы телесности могут обсуждаться как со спортсменом индивидуально, так в тренерском совете. В структуре полученного знания предписывается вносить корректирующие действия в режим спортивных нагрузок, организацию труда и отдыха, характер взаимо- действия «спортсмен-тренер», «спортсмен-сборная», «тренер-сборная».

Телесность спортсмена не является конечным образованием, психологические процессы, свойства и состояния личности в переживании и восприятии своего тела продолжают прижизненно развиваться. На этом основании, рациональным методом спортивного психолога и акмеолога является постоянное наблюдение, динамический мониторинг с накоплением эмпирической базы данных.

\section{Список литературы:}

1. Тхостов А.Ш. Психология телесности. М.: Смысл, 2002.

2. Акчурин Б.Г. Телесность как проявление человеческого потенциала и как валеологическая ценность // Теория и практика физической культуры. 2005. № 6.

3. Розин В.М. Концепция здоровья. М., 2011.

4. Подорога В.А. Полное и рассечённое. Политики тела. Материалы к истории базовых образов. Психология телесности: между душой телом. М.: АСТ, 2007.

5. Газарова Е.А. Тело и телесность: психологический анализ // Психология телесности: между душой и телом. М.: АСТ, 2007.

6. Баскаков В.Ю. Телесно-ориентированная психотерапия и психотехника: обобщение и сравнительный анализ существующих подходов // Телесность человека: междисциплинарные исследования. М., 1993.

7. Андрющенко А.В., Бескова Д.А. Телесность с точки зрения психосоматического континуума «здоровье - болезнь» // Телесность как эпистемиологический феномен / Под общ. ред. И.А. Бесковой. М.: ИФ РАН, 2009.

8. Архипова С.В. Особенности социокультурной телесности в современном обществе // Вопросы культурологии. 2011. № 11.

9. Фрумкин К.Г. Человеческая телесность в структуре будущего мира // Свободная мысль - XXI. 2005. № 1.

10. Чернявская Ю.В. Динамика советской телесности // Человек. 2011. № 6.

11. Кудряшов Н.И. Целительное движение. Пружинная сила. М.: Питер, 2002.

12. Блеер А.Н. Средства и методы совершенствования соревновательной надёжности борцов греко-римского стиля: Дис. ... канд. пед. наук. М., 1998.

13. Гожин В.В., Дементьев В.Л. Тревожность спортсмена-единоборца и его обусловленность индивидуальными свойствами высшей нервной деятельности // Спортивный психолог. 2010. № 2(20).

14. Ушаков А.Ф., Дементьев В.Л. Формирование и проявление характера у спортсмена-единоборца // Спортивный психолог. 2010. № 1(19).

15. Сопов В.Ф. Теория и практика психологической подготовки в современном спорте: Методическое пособие. М., 2010.

16. Казаков Ю.Н. Психическое здоровье - основополагающая целостность личности. М.: РАГС при Президенте РФ, 2005.

17. Казаков Ю.Н. Личностное здоровье: понятийно-категориальные основы. М.: РАСН, 2014.

18. Деркач А.А. Оптимизация устойчивости психического здоровья государственных служащих к экстремальным ситуациям. Пятигорск: Северо-Кавказская Академия Государственной Службы, Пятигорский филиал, 2008.

19. Алюшин А.Л., Князева Е.Н. Телесный подход в когнитивной науке // Философские науки. 2009. № 2.

20. Chapman Mike. Wrestling Tough. Human Kinetics Publishers, 2005.

21. Apitsch E. Anxiety in Sport. FEPSAC, 1983.

22. Horn Thelma S. Advances in Sport Psychology. Human Kinetics, 2008.

23. Lowen, Alexander. Aggression and violence in the Individual. Institute of Bioenergetic Analysis, 1969.

24. Pierrakos John. A Way of Life: Core Energetics. Bloomington, IN. iUniverse Inc., 2004.

25. Stuart J.H. Biddle. European Perspectives on Exercise and Sport Psychology. Champaign, IL: Human Kinetics, 1995.

\section{References (transliteration):}

1. Tkhostov A.Sh. Psikhologiya telesnosti. M.: Smysl, 2002.

2. Akchurin B.G. Telesnost' kak proyavlenie chelovecheskogo potentsiala i kak valeologicheskaya tsennost' // Teoriya i praktika fizicheskoi kul'tury. 2005. № 6.

3. Rozin V.M. Kontseptsiya zdorov'ya. M., 2011.

4. Podoroga V.A. Polnoe i rassechennoe. Politiki tela. Materialy k istorii bazovykh obrazov. Psikhologiya telesnosti: mezhdu dushoi telom. M.: AST, 2007.

5. Gazarova E.A. Telo i telesnost': psikhologicheskii analiz // Psikhologiya telesnosti: mezhdu dushoi i telom. M.: AST, 2007. 
6. Baskakov V.Yu. Telesno-orientirovannaya psikhoterapiya i psikhotekhnika: obobshchenie i sravnitel'nyi analiz sushchestvuyushchikh podkhodov // Telesnost' cheloveka: mezhdistsiplinarnye issledovaniya. M., 1993.

7. Andryushchenko A.V., Beskova D.A. Telesnost's tochki zreniya psikhosomaticheskogo kontinuuma «zdorov'e - bolezn'» // Telesnost' kak epistemiologicheskii fenomen / Pod obshch. red. I.A. Beskovoi. M.: IF RAN, 2009.

8. Arkhipova S.V. Osobennosti sotsiokul'turnoi telesnosti v sovremennom obshchestve // Voprosy kul'turologii. 2011 . № 11.

9. Frumkin K.G. Chelovecheskaya telesnost' v strukture budushchego mira // Svobodnaya mysl' - XXI. 2005 . № 1.

10. Chernyavskaya Yu.V. Dinamika sovetskoi telesnosti // Chelovek. 2011. № 6.

11. Kudryashov N.I. Tselitel'noe dvizhenie. Pruzhinnaya sila. M.: Piter, 2002.

12. Bleer A.N. Sredstva i metody sovershenstvovaniya sorevnovatel'noi nadezhnosti bortsov greko-rimskogo stilya: Dis. ... kand. ped. nauk. M., 1998.

13. Gozhin V.V., Dement'ev V.L. Trevozhnost' sportsmena-edinobortsa i ego obuslovlennost' individual'nymi svoistvami vysshei nervnoi deyatel'nosti // Sportivnyi psikholog. 2010. № 2(20).

14. Ushakov A.F., Dement'ev V.L. Formirovanie i proyavlenie kharaktera u sportsmena-edinobortsa // Sportivnyi psikholog. 2010. № 1(19).

15. Sopov V.F. Teoriya i praktika psikhologicheskoi podgotovki v sovremennom sporte: Metodicheskoe posobie. M., 2010.

16. Kazakov Yu.N. Psikhicheskoe zdorov'e - osnovopolagayushchaya tselostnost' lichnosti. M.: RAGS pri Prezidente RF, 2005.

17. Kazakov Yu.N. Lichnostnoe zdorov'e: ponyatiino-kategorial'nye osnovy. M.: RASN, 2014.

18. Derkach A.A. Optimizatsiya ustoichivosti psikhicheskogo zdorov'ya gosudarstvennykh sluzhashchikh $\mathrm{k}$ ekstremal'nym situatsiyam. Pyatigorsk: Severo-Kavkazskaya Akademiya Gosudarstvennoi Sluzhby, Pyatigorskii filial, 2008.

19. Alyushin A.L., Knyazeva E.N. Telesnyi podkhod v kognitivnoi nauke // Filosofskie nauki. 2009. № 2.

20. Chapman Mike. Wrestling Tough. Human Kinetics Publishers, 2005.

21. Apitsch E. Anxiety in Sport. FEPSAC, 1983.

22. Horn Thelma S. Advances in Sport Psychology. Human Kinetics, 2008.

23. Lowen, Alexander. Aggression and violence in the Individual. Institute of Bioenergetic Analysis, 1969.

24. Pierrakos John. A Way of Life: Core Energetics. Bloomington, IN. iUniverse Inc., 2004.

25. Stuart J.H. Biddle. European Perspectives on Exercise and Sport Psychology. Champaign, IL: Human Kinetics, 1995. 